\title{
Development of Novel Bread by Combining Seaweed Kappaphycus alvarezii from Sri Lanka and Saccharomyces cerevisiae Isolated from Nectarine
}

\author{
Noriko Komatsuzaki ${ }^{1}$, Sayoko Arai ${ }^{1}$, Shinobu Fujihara ${ }^{1}$, Jun Shima ${ }^{2}$, Rathnayake Saman Wijesekara ${ }^{3}$ and M. \\ Dileepa S. T. de Croos ${ }^{3}$ \\ 1. Department of Human Nutrition, Seitoku University, 550 Iwase Matsudo, Chiba 271-8555, Japan \\ 2. Faculty of Agriculture, Ryukoku University, 1-5 Yokototani, Seta Oe-Cho, Otsu, Shiga 520-2194, Japan \\ 3. Department of Aquaculture and Fisheries, Faculty of Livestock, Fisheries and Nutrition, Wayamba University of Sri Lanka, \\ Gonawila (NWP) 60170, Sri Lanka
}

\begin{abstract}
Seaweeds are not used as much for edible use although many kinds of seaweed are collected in Sri Lanka. The objective of this study was to develop high quality bread using seaweed, Kappaphycus alvarezii collected from Sri Lanka, and wild yeast, Saccharomyces cerevisiae isolated from nectarine in Japan. Dietary fiber in K. alvarezii, Japanese sea weeds, Wakame and Aosa contained 48.1, 31.7 and $29.1 \mathrm{~g} / 100 \mathrm{~g}$, respectively. The amount of total organic acid increased in garlic bread compared to bread without garlic. The best swelling properties were evident in the bread with K. alvarezii $(0.5 \%)$ and garlic. The bread including $K$. alvarezii increased the fermentative power of wild yeast while the addition of garlic increased the degree of swelling of the dough. In the sensory testing, the bread with K. alvarezii $(0.5 \%)$ and garlic was favored for the fineness of its texture and had the most preferred texture. It is possible to develop seaweed bread that is rich in dietary fiber and has excellent flavor by adding a suitable amount of garlic during the fermentation process.
\end{abstract}

Key words: Kappaphycus alvarezii, Saccharomyces cerevisiae, organic acids, bread making.

\section{Introduction}

In 2016, the consumption of seaweeds per capita in Japan was $10.9 \mathrm{~g} / \mathrm{d}$ [1]. Seaweeds have been eaten since ancient times throughout Japan. However, seaweeds are not eaten as frequently outside of Japan. Seaweeds are not used as much for edible use although many kinds of seaweeds are collected in Sri Lanka. Kappaphycus alvarezii is red algae, used as the major commercial source of carrageenan, which is widely utilized as a gelling and stabilizing agent for some food products [2]. It was reported that this seaweed, when used as a food supplement, prevents diet-induced metabolic syndrome in rats [3]. A study was conducted to develop an herbal porridge and a

Corresponding author: Noriko Komatsuzaki, Ph.D., research field: food microbiology. bun that incorporated seaweed using $K$. alvarezii because there has been a tradition of consuming seaweeds as sea vegetables since ancient times in Sri Lanka $[4,5]$.

Baker's yeast, or Saccharomyces cerevisiae, is an essential ingredient in bakery products produced by dough fermentation [6]. The main function of baker's yeast in bread baking is to increase dough volume through the production of gas $\left(\mathrm{CO}_{2}\right)$ during fermentation [7]. Previously, it was showed that seven wild yeasts isolated from leaves of apple (10-2), seed of nectarine (9-3) and humus (1-2) had fermentation abilities suitable for bread making [8]. The ethanol and $\mathrm{CO}_{2}$ production by $\mathrm{S}$. cerevisiae isolated from the leaves of apple (10-2) were the highest among the strains. The total acid contents of $S$. cerevisiae isolated the seed of nectarine (9-3). 
The aim of this study was to develop unique bread having a high nutritive value using $K$. alvarezii and wild yeast. In fermentation process, yeast generates organic acids such as succinic acid and malic acid [8]. These organic acids are associated with the flavor and taste of bread made with yeast $[9,10]$. The amount of organic acid contained in the bread was analyzed by using high-performance liquid chromatography (HPLC) analysis.

\section{Materials and Methods}

\subsection{Sample Collection and Pretreatment}

$K$. alvarezii was harvested from the Jaffna area in Sri Lanka, in March 2016. It was dried in solar dryer for 3-5 d without direct sunlight. Drying temperature of the solar dryer was $50-56{ }^{\circ} \mathrm{C}$. Relative humidity (RH) inside the drying chamber was $40 \%-60 \%$. Weather condition outside the dryer was $30{ }^{\circ} \mathrm{C}$ and RH $85 \%$. Drying sample was grounded using a blender prior to further analysis (Fig. 1). The composition analysis of $K$. alvarezii was conducted following the Association of Official Analytical Chemists (AOAC) method at the Japan Chemical Analysis Center in Tokyo, Japan. Dietary fiber was analyzed using AOAC 991.43 [11]. To determine the total dietary fiber (TDF), K. alvarezii was digested with three enzymes (protease, amylase, and amyloglucosidase) to break down starch and protein. TDF residue was washed with $95 \%$ ethanol and acetone, dried, and weighed. TDF residue values were

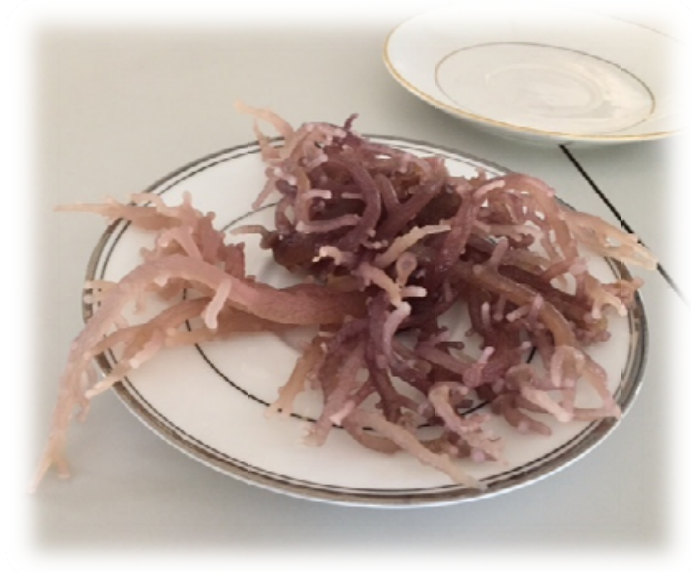

(a)

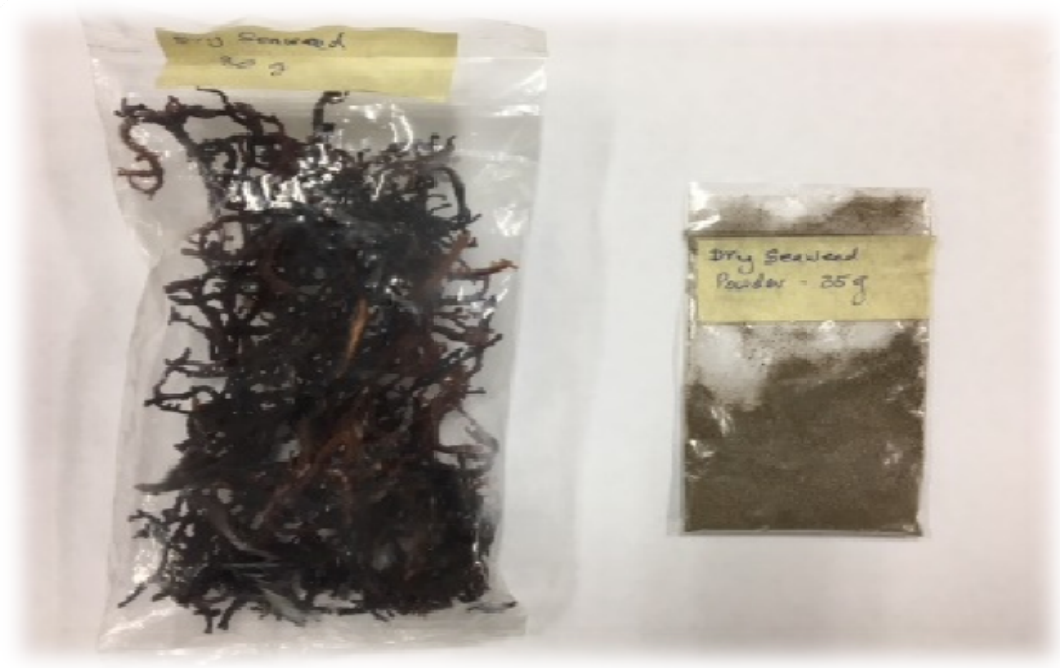

(b)

Fig. 1 The seaweed from Sri Lanka: (a) K. alvarezii; (b) drid K. alvarezii and powder. 
corrected for protein, ash and blank. TDF was the sum of these two amounts.

Commercially sold dried Wakame, Undaria pinnatifida (brown algae) and dried Aosa, Ulva linnaeus (green algae) were purchased from Riken Food Co., Ltd, and Isekanbutsu Co., Ltd in Japan, in April 2016. Wakame and Aosa were ground using a blender for bread-making.

\subsection{Media and Cultivation Conditions}

The molasses medium contained $30 \mathrm{~g}$ of sugar (calculated as sucrose), $2.25 \mathrm{~g}$ of urea and $0.46 \mathrm{~g}$ of $\mathrm{KH}_{2} \mathrm{PO}_{4}$. The yeast extract peptone dextrose (YPD) medium contained $10 \mathrm{~g}$ of yeast extract (Difco), $20 \mathrm{~g}$ of peptone (Difco) and $20 \mathrm{~g}$ of glucose (per liter). Wild yeast 9-3 (S. cerevisiae) isolated from nectarine was used [8]. The preparation of compressed yeast was carried out according to the method of Nishida et al. [7]. A 50-mL volume of YPD medium was placed in a $100-\mathrm{mL}$ flask and adjusted to $\mathrm{pH} 5.5-6.0$ with 1.0 $\mathrm{N} \mathrm{HCl}$ prior to autoclaving. Wild yeast was grown in the flask for $24 \mathrm{~h}$ at $30{ }^{\circ} \mathrm{C}$. The culture was transferred by means of sterile inoculation loops to $450 \mathrm{~mL}$ of the molasses medium in a flask. The flask was incubated at $30{ }^{\circ} \mathrm{C}$ for $2 \mathrm{~d}$ with $130 \mathrm{rpm}$ shaking rate. Fermentation samples were centrifuged at 3,000 rpm for $10 \mathrm{~min}$. The supernatant was removed, and the collected wild yeasts were used in the bread-making.

\subsection{Bread-Making}

The bread-making was performed three times. The seaweed and garlic used for bread making are shown in Table 1. In the first experiment, commercial baker's yeast $+K$. alvarezii $(1 \%)$ was used as control $(\mathrm{C} 1)$, wild yeast $+K$. alvarezii $(1 \%)$ as $K 1$, wild yeast + Wakame (1\%) as W1, and wild yeast + Aosa (1\%) as A1. In the second experiment, fresh garlic was added for the purpose of suppressing the odor of the $K$. alvarezii seaweed, Wild yeast $+K$. alvarezii $(0.5 \%)$ as $\mathrm{K} 0.5$, wild yeast $+K$. alvarezii $(1.5 \%)$ as $\mathrm{K} 1.5$, wild yeast $+K$. alvarezii $(0.5 \%)+$ garlic $(1 \mathrm{~g})$ as $\mathrm{K} 0.5 \mathrm{G}$, and wild yeast $+K$. alvarezii $(1.5 \%)+$ garlic $(1 \mathrm{~g})$ as K1.5G. As a result of the bread making, the ratio of the addition of $K$. alvarezii was determined, and four kinds of bread were made to compare the influence of Aosa and Wakame on the physical characteristics of bread. The ingredients for bread making are shown in Table 2. The ingredients and seaweed were put into a Siroca home bakery SHB-112 (Siroca, Inc.), and were baked automatically. The first fermentation time was $40 \mathrm{~min}$ and the second fermentation time was $50 \mathrm{~min}$. After baking, the weight of these breads was measured. The height of these bread was measured in order to check the volume rise of bread.

\subsection{Sensory Evaluation}

In order to clarify whether the bread containing $K$. alvarezii is acceptable to a Japanese population, the sensory evaluation was conducted using the bread made with Japanese seaweed. The sensory evaluation was performed using a method based on the appearance, scent, sweetness, softness (texture), and

Table 1 Seaweed and garlic used for bread making.

\begin{tabular}{lll}
\hline & Seaweed & Fresh garlic \\
\hline $\mathrm{C} 1 *$ & Kappaphycus alvarezii $(1 \%)$ & \\
$\mathrm{K} 1$ & K. alvarezii $(1 \%)$ & \\
$\mathrm{W} 1$ & Wakame $(1 \%)$ & \\
$\mathrm{A} 1$ & Aosa $(1 \%)$ & \\
$\mathrm{K} 0.5$ & K. alvarezii $(0.5 \%)$ & \\
$\mathrm{K} 1.5$ & K. alvarezii $(1.5 \%)$ & $1 \mathrm{~g}$ \\
$\mathrm{~K} 0.5 \mathrm{G}$ & K. alvarezii $(0.5 \%)$ & $1 \mathrm{~g}$ \\
$\mathrm{~K} 1.5 \mathrm{G}$ & K. alvarezii $(1.5 \%)$ & \\
\hline
\end{tabular}

* Commercial baker's yeast. 
Table 2 Ingredients for bread-making.

\begin{tabular}{lll}
\hline & Ratio $(\%)$ & Amount of use $(\mathrm{g})$ \\
\hline Hard flour & 100 & 320 \\
Butter & 8 & 25 \\
Sucrose & 4.7 & 15 \\
Honey & 3.2 & 10 \\
Salt & 1.8 & 6 \\
Skim milk & 2.5 & 8 \\
Yeast (dry yeast) & $2.8(1)$ & $9(3.2)$ \\
Water & 68 & 220 \\
\hline
\end{tabular}

overall preference for four kinds of confectionery breads. The panel included 30 female students of the Department of Human Nutrition at Seitoku University. The analysis method was verified by Spearman's rank correlation coefficient. For the analysis of the results, Friedman's test was conducted. Differences in values between groups were tested by Scheffe's multiple-range test. A $p$-value of less than 0.05 was considered statistically significant.

\subsection{Analysis of Organic Acid Composition}

The bread was lyophilized and powdered by a grinder. A $1 \mathrm{~g}$ sample was extracted with $10 \mathrm{~mL}$ of $70 \%$ ethanol at $50{ }^{\circ} \mathrm{C}$ for $30 \mathrm{~min}$ and centrifuged at $1,500 \mathrm{~g}$ for $10 \mathrm{~min}$, at $4{ }^{\circ} \mathrm{C}$. The residue was further extracted two more times, and all the extracts were combined and evaporated using rotary vacuum evaporation. The concentrates were diluted to $3 \mathrm{mmol} / \mathrm{L}$ of the perchloric solution and filtered through $0.45 \mu \mathrm{m}$ filters (Millipore, Molford, MA, USA).

An organic acid in the four breads was analyzed by HPLC (Hitachi UV L-7405). The samples were applied to a GL-C610H-S column $(300 \mathrm{~mm} \times 7.8 \mathrm{~mm}$; eluent, $3 \mathrm{mmol} / \mathrm{L}$ of perchloric solution, reaction liquid, bromothymol blue solution, flow rate, 0.5 $\mathrm{mL} / \mathrm{min}$, oven temperature, $60{ }^{\circ} \mathrm{C}$, injection volume, $20 \mu \mathrm{L}$, Hitachi Chemical Co, Ltd, Japan), and visible (VIS) absorbance was measured at $440 \mathrm{~nm}$ [12].

\section{Results and Discussion}

\subsection{Characterization of Seaweeds}

The nutritional composition of $K$. alvarezii was compared with that of Japanese seaweeds (Table 3). Although the calcium level in K. alvarezii was lower than that in Japanese seaweeds, the carbohydrate, fiber and ash contents in $K$. alvarezii were higher. $K$. alvarezii is a red alga with particularly high carbohydrate content. Functional foods such as red seaweeds could serve as potential therapeutic options for metabolic syndrome, a constellation of risk factors for type 2 diabetes and cardiovascular disease [13, 14]. There are some evidences that carrageenan of Kappaphycus has antioxidant and blood lipid-lowering properties [15, 16]. Wanyonyi et al. [3] reported that the major biochemical components of dried Kappaphycus are carrageenan, a soluble fiber at $34.6 \%$, and a low overall energy content for whole seaweed. It was assumed that the K. alvarezii from Sri Lanka contained a large quantity of carrageenan. Quantification of carrageenan in the K. alvarezii used in this study is necessary.

\subsection{Characterization of Seaweed Bread}

In the first experiment, the degree of swelling in the four kinds of breads was nearly the same. However, the weight of the $\mathrm{K} 1$ was lower than that of the $\mathrm{C} 1$, $\mathrm{W} 1$ and A1. K. alvarezii has a peculiar seaweed smell, and thus is not popular among the Japanese population. Therefore, the bread was made with garlic added for a deodorization effect. The effect of different concentrations of $K$. alvarezii on bread is shown in Fig. 2. Figs. $2 \mathrm{a}$ and $2 \mathrm{~b}$ show the breads made from K0.5, K1.5, K0.5G and K1.5G. Fig. 2c shows the breads made from $\mathrm{W} 1$ and $\mathrm{K} 1$. The heights of these 
Table 3 Nutritional composition of seaweeds.

\begin{tabular}{llllllllllll}
\hline & $\begin{array}{l}\text { Energy } \\
(\mathrm{kcal})\end{array}$ & $\begin{array}{l}\text { Water } \\
(\mathrm{g})\end{array}$ & $\begin{array}{l}\text { Protein } \\
(\mathrm{g})\end{array}$ & $\begin{array}{l}\text { Fat } \\
(\mathrm{g})\end{array}$ & $\begin{array}{l}\text { Carbohydrate } \\
(\mathrm{g})\end{array}$ & $\begin{array}{l}\text { Fiber } \\
(\mathrm{g})\end{array}$ & $\begin{array}{l}\text { Ash } \\
(\mathrm{g})\end{array}$ & $\begin{array}{l}\text { Potassium } \\
(\mathrm{mg})\end{array}$ & $\begin{array}{l}\text { Calcium } \\
(\mathrm{mg})\end{array}$ & $\begin{array}{l}\text { Phosphorus } \\
(\mathrm{mg})\end{array}$ & $\begin{array}{l}\text { Vitamin C } \\
(\mathrm{mg})\end{array}$ \\
\hline K. alvarezii $^{1}$ & 121 & 8.6 & 3.6 & 1.5 & 53.7 & 48.1 & 32.6 & 2,384 & 181 & 12 & 20 \\
Wakame $^{2}$ & 134 & 7.2 & 16.7 & 1.2 & 47.4 & 31.7 & 27.5 & 1,800 & 960 & 320 & 20 \\
Aosa $^{3}$ & 130 & 16.9 & 22.1 & 0.6 & 41.7 & 29.1 & 18.7 & 3,200 & 490 & 160 & 25 \\
\hline
\end{tabular}

${ }^{1}$ K. alvarezii (red algae); ${ }^{2}$ Undaria pinnatifida (brown algae); ${ }^{3}$ Ulva linnaeus (green algae).

${ }^{2,3}$ Source: Standard Tables of Food Composition in Japan 2017.

breads were measured, and the results were as follows: (1) $12.5 \mathrm{~cm}$ and $12.3 \mathrm{~cm}$; (2) $13.2 \mathrm{~cm}$ and $13.4 \mathrm{~cm}$. The breads with garlic were higher than the breads not containing garlic. It was reported that fermentation was accelerated when yeast was cultured in a medium containing $0.17 \%$ to $0.35 \%$ garlic [17]. However, the growth of the yeast was inhibited when the amount of garlic added was more than $7 \%$. It is important to provide fluffy bread in a fermentation process [18]. Garlic has several functional compounds such as flavonoids and antioxidants [19]. In this study, it was suggested that some ingredients of garlic increased the fermentation ability of yeast. It was planned to perform fermentation tests at various garlic concentrations to determine the optimum garlic concentration in bread-making.

\subsection{Evaluation of Seaweed Bread}

Table 4 shows the results of the sensory testing of the four types of bread. The bread most favored by students from the Department of Human Nutrition at Seitoku University was W1 because of its favorable flavor, preferable taste and overall quality. In regards to the fineness of the texture and the preferred texture, the most favored was $\mathrm{K} 0.5 \mathrm{G}$. The favorable flavor of W1 was significantly different from those of K0.5 and A1 $(p<0.001)$. There was a significant difference between $\mathrm{A} 1$ and $\mathrm{W} 1$ in the comprehensive evaluation $(p<0.05)$. Seaweeds are daily ingested such as miso soup and salad in Japan [20]. The Japanese students in this study had no experience of eating $K$. alvarezii. It was supposed that the breads made with Wakame were popular because the crushed Wakame grain was large and the original seaweed taste could be directly enjoyed.

Table 3 shows the organic acid content of the breads. Citric acid, malic acid, succinic acid, lactic acid and acetic acid were detected in all of the breads. The highest total organic acid content was in K0.5G. Slight amounts of pyloglutamic acid were contained in $\mathrm{K} 0.5 \mathrm{G}$ and $\mathrm{K} 1.5 \mathrm{G}$. Garlic was added to these breads during the bread-making process. The organic acid production of yeast results from the tricarboxylic acid cycle operating continuously, producing succinic acid and malic acid [21]. These organic acids are associated with the flavor and taste of bread made with yeast [9, 22].

In the sensory testing, although there were no significant differences between $\mathrm{K} 0.5$ and $\mathrm{K} 0.5 \mathrm{G}$, $\mathrm{K} 0.5 \mathrm{G}$ was favored for the fineness of its texture and had the most preferred texture (Table 4). Additionally, the total organic acid level in the bread with $K$. alvarezi and garlic was the highest (Table 5). Some recipes call for broken rice to accelerate fermentation [23]. It is possible that some ingredients in the garlic accelerate the fermentation of yeast during bread-making as well as report of Mizuma [17]. 


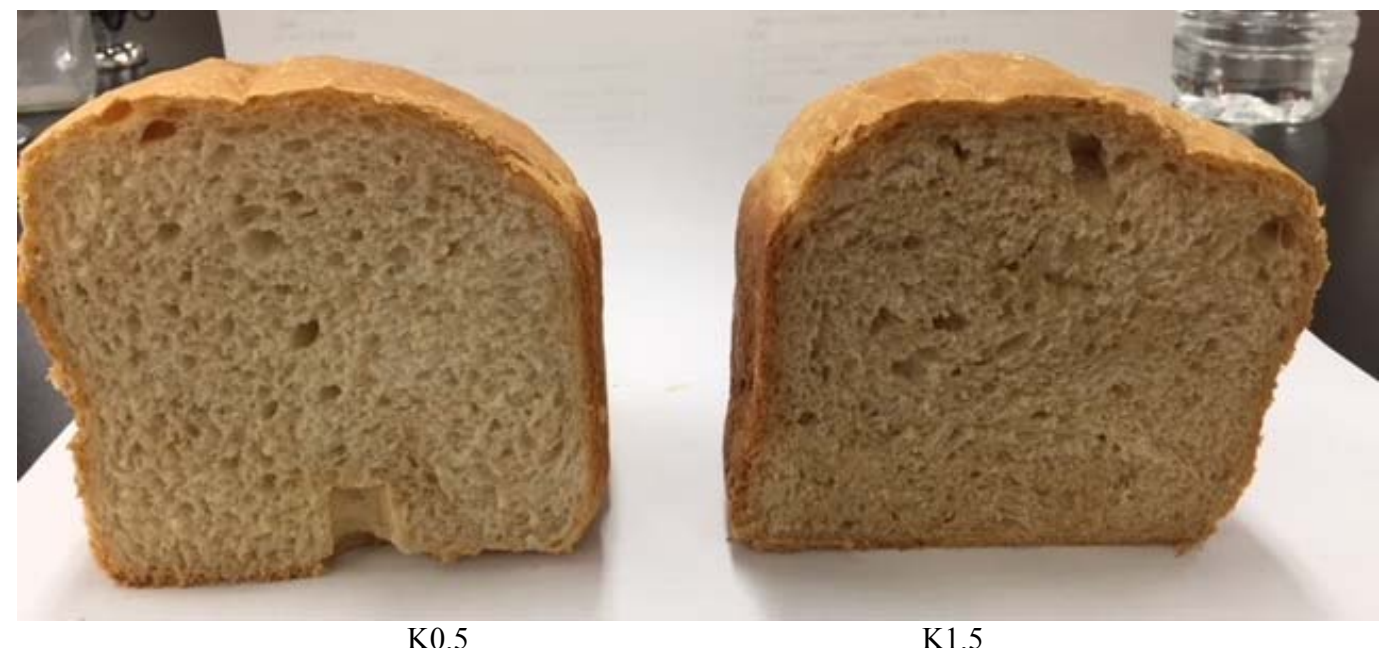

(a)

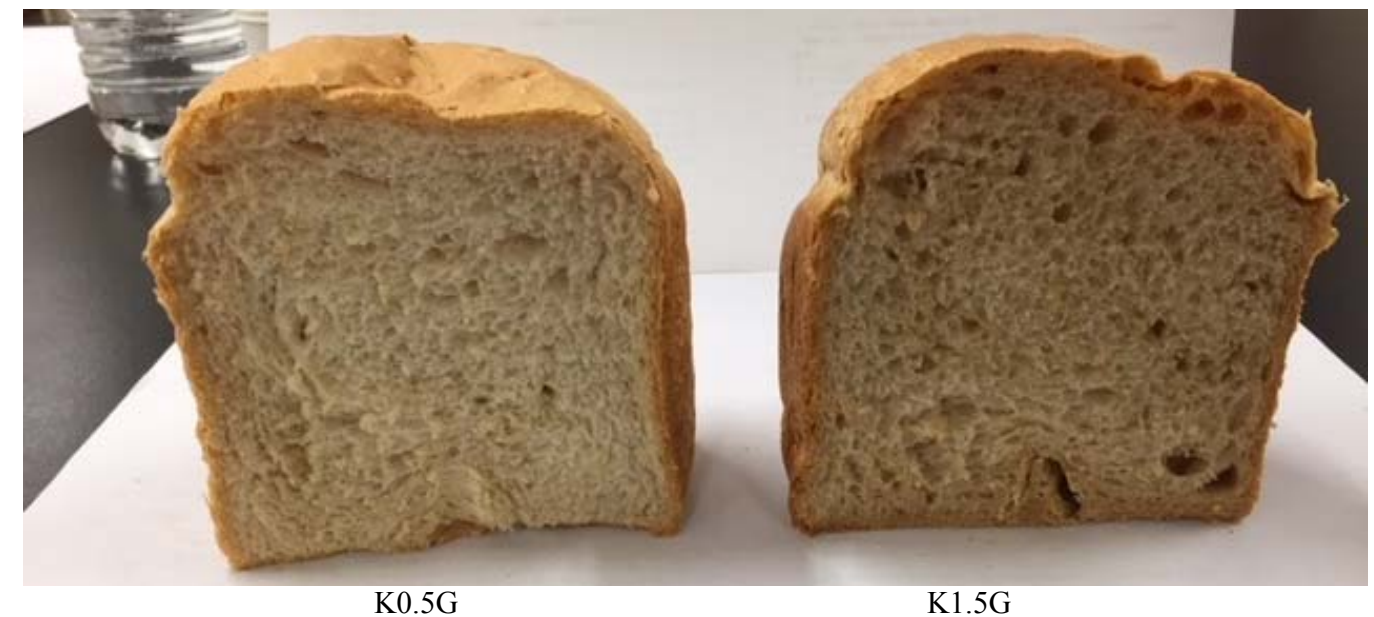

(b)

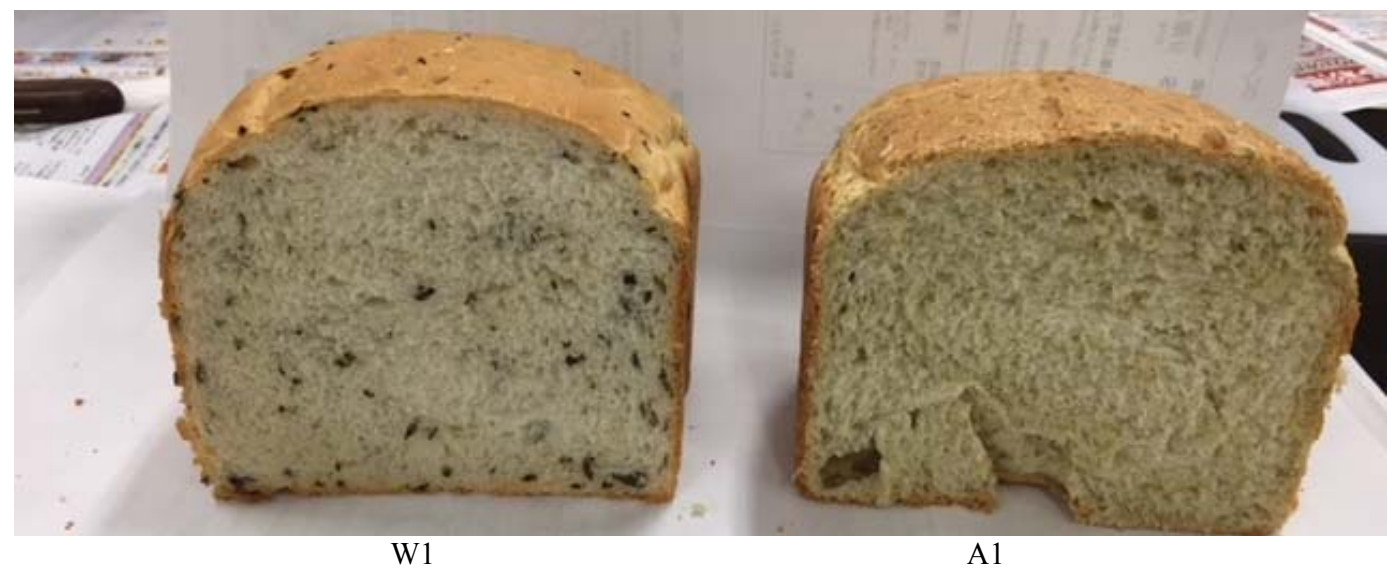

(c)

Fig. 2 Effect of different concentration of $K$. alvarezii on bread.

(a) Left side is K. alvarezii $(0.5 \%)$, right side is K. alvarezii $(1.5 \%)$; (b) left side is K. alvarezii $(0.5 \%)+$ garlic $(1 \mathrm{~g})$, right side is $K$. alvarezii $(1.5 \%)+$ garlic $(1 \mathrm{~g})$; (c) left side is Wakame $(1 \%)$, right side is Aosa $(1 \%)$. 
Sri Lanka and Saccharomyces cerevisiae Isolated from Nectarine

Table 4 Sensory testing of the four types of bread.

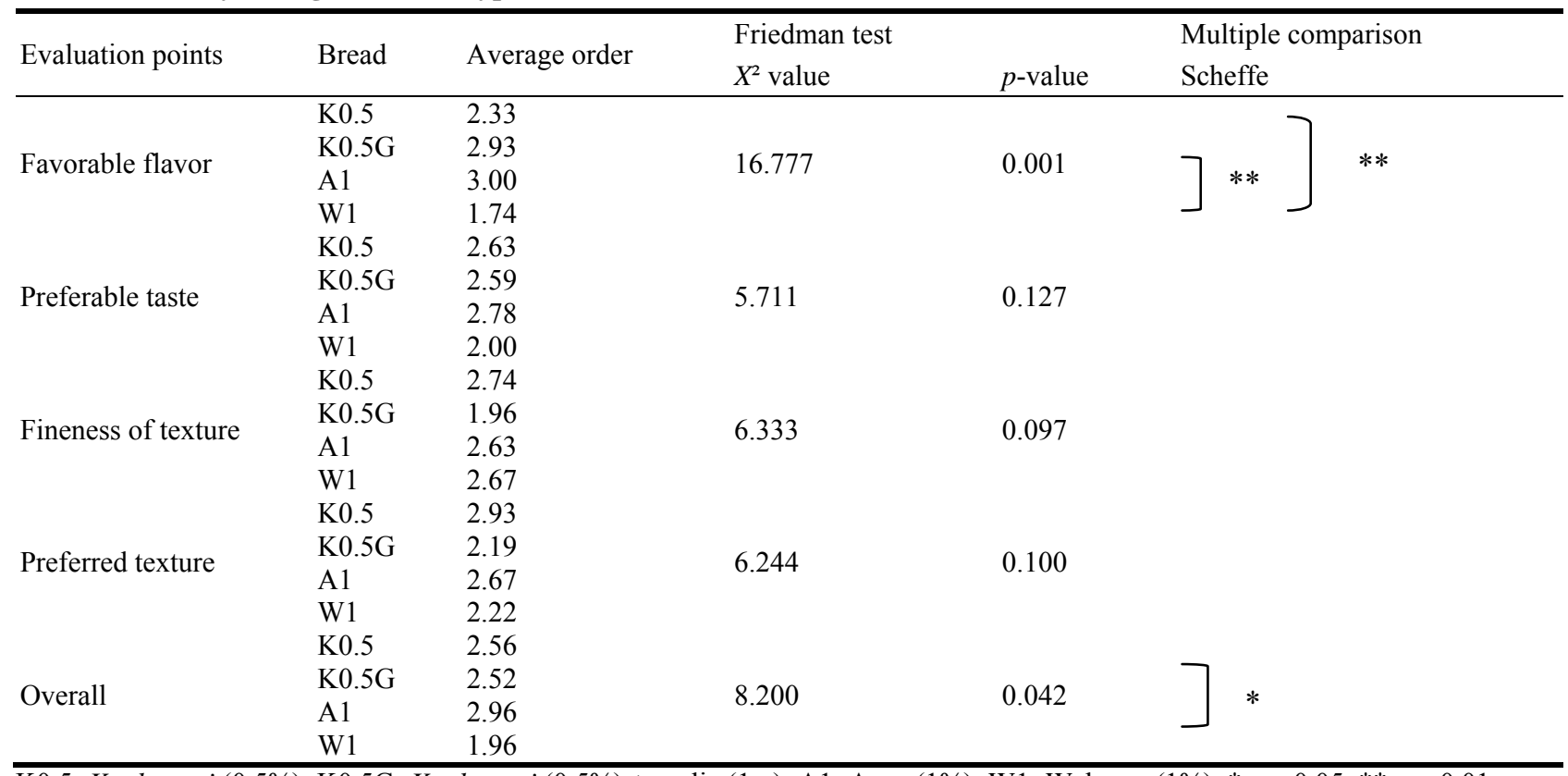

K0.5: K. alvarezi (0.5\%); K0.5G: K. alvarezi (0.5\%)+ garlic (1 g); A1: Aosa (1\%); W1: Wakame (1\%). ${ }^{*} p<0.05,{ }^{* *} p<0.01$.

Table 5 Organic acid in the bread $(\mathrm{mg} / \mathrm{g})$.

\begin{tabular}{llllllll}
\hline & K0.5 & K1.5 & K0.5G & K1.5G & W1 & A1 & K1 \\
\hline Citric acid & 1.11 & 1.02 & 1.17 & 1.23 & 0.85 & 1.04 & 1.19 \\
Malic acid & 0.11 & 0.15 & 0.04 & 0.17 & 0.39 & 0.18 & 0.45 \\
Succinic acid & 0.29 & 0.29 & 0.39 & 0.35 & 0.18 & 0.29 & 0.21 \\
Lactic acid & 0.48 & 0.34 & 0.61 & 0.39 & 0.05 & 0.38 & 0.09 \\
Acetic acid & 0.09 & 0.11 & 0.15 & 0.12 & 0.06 & 0.10 & 0.11 \\
Pyroglutamic acid & - & - & 0.04 & 0.03 & - & 0.01 & - \\
\hline Total & 2.08 & 1.89 & 2.40 & 2.29 & 1.54 & 2.01 & 2.05 \\
\hline K0.5: K. alvarezi (0.5\%), K1.5: K. alvarezi (1.5\%); K0.5G: K. alvarezi (0.5\%)+ garlic (1 g); K1.5G: K. alvarezi (1.5\%)+ garlic (1 \\
g); W1: Wakame (1\%), A1: Aosa (1\%), K1: K. alvarezi (1\%).
\end{tabular}

\section{Conclusions}

This study demonstrated the strong potential to make fermented food using Sri Lankan seaweeds and Japanese wild yeasts. It was found that it contained much dietary fiber in K. alvarezii. It is possible to develop seaweed bread that is rich in dietary fiber and has excellent flavor by adding a suitable amount of garlic during the fermentation process.

\section{Acknowledgment}

The authors would like to thank the students of the Department of Human Nutrition of Seitoku University who cooperated with the sensory evaluation of the seaweed bread.

\section{References}

[1] Ministry of Health, Labour and Welfare, Japan. 2016. The National Health and Nutrition Survey in Japan. Tokyo, Japan: Diichi Press.

[2] Li, H., Liu, J., Zhang, L., and Pang, T. 2016. "Antioxidant Responses and Photosynthetic Behaviors of Kappaphycus alvarezii and Kappaphycus striatum (Rhodophyta, Solieriaceae) during Low Temperature Stress." Bot Stud 57: 21.

[3] Wanyonyi, S., Preez, R., Brown, L., Paul, N. A., and Panchal, S. K. 2017. "Kappaphycus alvarezii as Food Supplement Prevents Diet-Induced Metabolic Syndrome in Rats." Nutrients 9: 1261.

[4] Anushika, H. L. G., Wijesekara, R. G. S., De Croose, M. D. S. T., and Komatsuzaki, N. 2016. "Two Products Developments Using Seaweed Kappaphycus alvarezii: New Herbal Porridge and Value Addition for Traditional 

Sri Lanka and Saccharomyces cerevisiae Isolated from Nectarine

Herbal Gruel 'KolaKenda'." Undergraduate Research Symposium, Faculty of Livestock, Fisheries and Nutrition, Wayamba University of Sri Lanka, 56. ISSN 2465-5821.

[5] Sithara, J. N., Wijesekara, R. G. S., Komatsuzaki, N., and De Croose, M. D. S. T. 2017. "Towards a Healthy-Food Culture: Fresh Fish Incorporated Bun with Nutritional Details." In Proceedings of the Twenty Third Scientific Sessions of the Sri Lanka Association for Fisheries and Aquatic Resources, 44.

[6] Tokashiki, T., Yamamoto, H., Watanabe, H., Nakajima, R., and Shima, J. 2011. "A Functional Compound Contained in Sugar Cane Molasses Enhances the Fermentation Ability of Baker's Yeast in High-Sugar Gough.” J. Gen. Appl. Microbiol. 57: 303-7.

[7] Nishida, O., Kuwazaki, S., Suzuki, C., and Shima, J. 2004. "Superior Molasses Assimilation, Stress Tolerance, and Trehalose Accumulation of Baker's Yeast Isolated from Dried Sweet Potatoes (Hoshi-Imo)." Biosci. Biotechnol. Biochem. 68: 1442-8.

[8] Komatsuzaki, N., Okumura, R., Sakurai, M., Ueki, Y., and Shima, J. 2016. "Characteristics of Saccharomyces cerevisiae Isolated from Fruits and Humus: Their Suitability for Bread Making." Progress in Biological Sciences 6: 1-9.

[9] Kamakura, M., and Mayama, M. 2012. "Bread Making Property of Hanseniaspora meyeri, One of the Wild Yeast Isolates from Petal of Citrus sudachi." Bull. Shikoku. Univ. 34: 37-46.

[10] Kim, H. R., Kim, J. H., Bae, D. H., and Ahn, B. H. 2010. "Characterization of Yakju Brewed from Glutinous Rice and Wild-Type Yeast Strains Isolated from Nuruks." J. Microbiol. Biotechnol. 20: 1702-10.

[11] Sangronis, E., and Rebolledo, M. A. 1993. "Soluble, Insoluble, and Total Dietary Fiber in Cereals, Products Derived from Their Processing and Cereal-Based Commercial Products." Arch. Latinoam. Nutr. 43: 258-63.

[12] Yasui A. 2016. Standard Tables of Food Composition in Japan, Analytical Manual. Kenpakusha, 220-1. (in Japanese)

[13] Suresh, K. K., Ganesan, K., and Subba Rao, P. V. 2015.
"Seasonal Variation in Nutritional Composition of Kappaphycus alvarezii (Doty) Doty-An Edible Seaweed." J. Food. Sci. Technol. 52: 2751-60.

[14] Murata, M., Sano, Y., Ishihara, K., and Uchida, M. 2002. "Dietary Fish Oil and Undaria pinnatifida (Wakame) Synergistically Decrease Rat Serum and Liver Triacylglycerol.” J. Nutr. 132: 742-7.

[15] Raman, M., and Doble, M. 2015. "Carrageenan from Marine Red Kappaphycus alvarezii-A Functional Food to Prevent Colon Carcinogenesis." J. Funct. Food 15: 354-64.

[16] Matanjun, P., Mohamed, S., Muhammad, K., and Mustapha, N. M. 2010. “Comparison of Cardiovascular Protective Effect of Tropical Seaweeds, Kappaphycus alvarezii, Caulerpa lentillifera, and Sargassum polycystum, on High-Cholesterol/High-Fat Diet in Rats." J. Med. Food 13: 792-800.

[17] Mizuma, H. 2011. "Study on Action of Ginger Rhizome and Garlic Bulb on Growth and Fermentation Performance of Microbe and Its Application." M.Sc. thesis, Kochi University of Technology.

[18] Komatsuzaki, N., Kamishima, H., Fujihara, S., Ueki, Y., and Shima, J. 2016. "Fermentation Characteristics of Yeast Suitable for High-Sugar Dough.” J. Integr. Stud. Diet. Habits. 27: 15-21.

[19] Yang, C., Li, L., Yang, L., Lu, H., Wang, S., and Sun, G. 2018. "Anti-obesity and Hypolipidemic Effects of Garlic Oil and Onion Oil in Rats Fed a High-Fat Diet." Nutr. Metabo. 15: 43.

[20] Okuda, H. 1995. "Cooking of Seaweed." Journal of Cookery Science of Japan 28: 50-8.

[21] Asano, T. 2007. "Studies on Organic Acid Production by Sake Yeast." Journal of Bioscience Bioengineering 85: 63-8.

[22] Kinoshita-Komuro, Y., Kadokura, T., Kazuoka, T., Hosaka, K., and Nakata, H. 2008. "Characteristics of Yeasts Isolated from Plant Flowers and Their Properties on Sake Brewing.” J. Agric. Sci. Tokyo Univ. 53: 100-6.

[23] Gohel, V., and Duan, G. 2012. "Conventional Process for Ethanol Production from Indian Broken Rice and Pearl Millet.” Bioprocess Biosyst Eng. 35: 1297-308. 